\title{
INCREASING THE ECOLOGICAL LEVEL OF PUBLIC TRANSPORT IN THE CITY OF SOFIA
}

\author{
Iliya Gatovski ${ }^{1}$
}

\begin{abstract}
The paper explores some of the major factors affecting the environmental friendliness of urban bus transport, with a focus of the modernization of rolling stock and alternative sources of fuel. The surveys are based on an 11-year period, from 2008 to 2019, for which an analysis was made of how much emission reductions in buses with a higher Euro standard are being followed, as in the case of Sofia Motor Transport EAD in Sofia, Bulgaria. As a result, we conclude that transport research and innovation are crucial to ensuring fast, safe and clean transport for citizens and businesses in big cities. The transport sector is more than ever in need of innovative solutions, as the cost of transporting passengers will increase in value and time. This is especially urgent for Bulgaria as the available rolling stock is outdated and in need of renovation.
\end{abstract}

JEL Classification Numbers: L98, O18, R42, DOI: https://doi.org/10.12955/peb.v1.19

Keywords: urban transport, environmental friendliness, rolling stock, quality of transport service.

\section{Introduction}

Transport is a field of national economy that encompasses transport enterprises that provide services for payment. In recent years it has become one of the most dynamically developing sectors in Bulgaria, especially after overcoming the financial-economic crisis of 2007. To a great extent, the services provided by mass urban passenger transport, along with health care and education, form the social and economic climate in every city. These transport services are vital to the existence of all populated areas. They are a necessary prerequisite for the provision of other services such as: commercial service, vacation or tourism, traveling from home to work, etc. The territorial development and appeal of cities are largely determined by the condition and functioning of mass urban transport. According to S. Tzvetkova (2018), high-quality and socially effective transport guarantees high living standards for citizens and is more accessible to elderly people, family with children and humans with special needs.

Velikova (2019) summarizes the researches about sustainable transport development and points out that it is largely related to the economic development of the country. It is also a prerequisite for improving the state of the environment and raising the standard of living of the population. Achieving sustainable transport development is in line with the objectives of the European Transport Policy. In this regard, its targeted research areas are: reducing the harmful effects of transport on the environment, improving the security and safety of transport, increasing the mobility of people and goods and increasing the competitiveness of transport (Velikova, 2019). In this respect, the studies cited also relate to our researches and analyses - raising the environmental level of public transport will support its sustainable development and improve the living conditions in the country, both ecologically and economically.

The main thesis of the study is that the modernization of the rolling stock and the use of alternative fuel sources - i.e. natural gas, hydrogen buses, hybrid buses and buses that run on electricity, will reduce harmful emissions by over $50 \%$.

\section{State of the problem}

Although automobile transport is the primary pollutant and source of harmful emissions in the city of Sofia, they are predominantly generated by personal vehicles and barely $10 \%$ by bus transport. Like any major city with growing population, Sofia has also been facing the pressing issue of intensifying automobile traffic and the significant decline in the environment's quality. Automobiles are among the biggest pollutants in the city, emitting over 200 harmful substances as a result of the burning of liquid petroleum-based fuels. Traffic jams, which saturate the urban environment more and more, and not just during the so-called rush hour, also contribute significantly to the complication of this problem. Additionally, they increase noise pollution, cause more and more traffic accidents and loss of time during extended traveling from one point to another. All of this provokes the necessity for renewing and modernizing the rolling stock of bus transport in the capital. Reducing the harmful influence of buses on the environment in cities is crucial because they carry out over $50 \%$ of the transport activity in Sofia. According to Arnaudov (2013, p. 143-144) in recent years, the needs for transport services (freight and passenger) have been increasing, and at the same time the requirements for their quality have increased.

\footnotetext{
${ }^{1}$ University of National and World Economy, Faculty Economy of Infrastructure, Department „Economics of Transport and Energy“, gatovski@unwe.bg; i_gatovski@abv.bg
} 
According to Tzvetkova (2017), the indicators which describe and are connected with the quality of bus transport in the capital are highly unsatisfactory, which puts the necessity for their improvement on the agenda. This is due mainly to the poor condition and high average age of the rolling stock in bus passenger transport whose operation results in harmful emissions which pollute the environment, as well as noise pollution in the city. Citizens should shift their preferences from bus transport and personal vehicles to the subway which is the most environmentally friendly type of urban passenger transport. This is the only way to improve the indicators which determine the social effectiveness and quality of urban passenger transport.

\section{Research Data and Results}

In terms of work volume measured in mileage, "Capital Motor Transport" SJSC holds the largest share of the total run - namely, 59.5\% (35 500 thousand km). "Capital Electric Transport" SJSC is in second place with $24.0 \%$ (1400 thousand $\mathrm{km}$ ), followed by other bus freighters with $9 \%$ and "Metropolitan Sofia" SJSC with 7.5\% - 4200 thousand km. (CUM). Bus transport holds the largest share due to its advantages, especially the quality of the services it offers.

Tables 1, 2 and 3 present the changes in the number and structure of the rolling stock during the 20082019 period in terms of used fuel, size and average age.

\begin{tabular}{|cccccccc|}
\hline \multicolumn{3}{|c|}{ Table 1: Structure of the rolling stock in "Capital Motor Transport" SJSC } \\
\hline \multicolumn{3}{c}{ Bus Type } & \multicolumn{3}{c|}{ Number of Buses } & \multicolumn{3}{c|}{ Average Age } \\
Size & Engine & 2008 & 2019 & $\%$ & 2008 & 2019 & $\%$ \\
$\mathbf{1 2}-\mathbf{m}$ & diesel & 265 & 242 & $18.87 \%$ & 13.5 & 9.2 & $-12.66 \%$ \\
$\mathbf{1 8}-\mathbf{m}$ & diesel & 366 & 86 & $-61.48 \%$ & 19.2 & $18.7+$ & $1.80 \%$ \\
$\mathbf{1 2}-\mathbf{m}$ & natural gas & 24 & 82 & $-66.67 \%$ & 13.4 & 2.0 & $-33.02 \%$ \\
$\mathbf{1 8}-\mathbf{m}$ & natural gas & 0 & 186 & - & 0.0 & 3.0 & - \\
$\mathbf{1 2}-\mathbf{m}$ & electric & 0 & 20 & - & - & 1 & - \\
Total: & - & 655 & 616 & $-9.9 \%$ & 16.8 & 7.37 & $-37.5 \%$ \\
\hline
\end{tabular}

In terms of work volume measured in mileage, "Capital Motor Transport" SJSC holds the largest share of the total run - namely, 59.,5\% (35 500 thousand km). "Capital Electric Transport" SJSC is in second place with $24.0 \%$ (1400 thousand $\mathrm{km}$ ), followed by other bus freighters with $9 \%$ and "Metropolitan Sofia" SJSC with $7.5 \%$ (4200 thousand km). Bus transport holds the largest share due to its advantages, especially the quality of the services it offers.

\begin{tabular}{|} 
Table 2: List composition of buses according to size, assigned as of 31.12.2019 \\
\begin{tabular}{|c|c|c|c|}
\hline Year & $\begin{array}{c}\text { 18-m } \\
\text { (number) }\end{array}$ & $\begin{array}{c}\text { 12-m } \\
\text { (number) }\end{array}$ & $\begin{array}{c}\text { Total } \\
\text { (number) }\end{array}$ \\
\hline $\mathbf{2 0 0 8}$ & 366 & 289 & 655 \\
\hline $\mathbf{2 0 0 9}$ & 336 & 264 & 600 \\
\hline $\mathbf{2 0 1 0}$ & 321 & 274 & 595 \\
\hline $\mathbf{2 0 1 1}$ & 295 & 264 & 559 \\
\hline $\mathbf{2 0 1 2}$ & 294 & 263 & 557 \\
\hline $\mathbf{2 0 1 3}$ & 294 & 263 & 557 \\
\hline $\mathbf{2 0 1 4}$ & 335 & 261 & 596 \\
\hline $\mathbf{2 0 1 5}$ & 286 & 236 & 522 \\
\hline $\mathbf{2 0 1 6}$ & 267 & 323 & 590 \\
\hline $\mathbf{2 0 1 7}$ & 267 & 322 & 589 \\
\hline $\mathbf{2 0 1 8}$ & 254 & 367 & 621 \\
\hline $\mathbf{2 0 1 9}$ & 272 & 344 & 616 \\
\hline
\end{tabular} \\
\hline
\end{tabular}

In 2019 the assigned rolling stock at "Capital Motor Transport" SJSC consists of 616 buses, 272 of which are twin coach (18-meter) and 344 are single (12-meter). The average age of the rolling stock at "Capital Motor Transport" SJSC has been reduced to 7.3 years. The newly assigned 20 buses that run entirely on electricity also contribute to the improvement of the "Average Vehicle Age" indicator. 
The "Average Age of the Rolling Stock" indicator at "Capital Motor Transport" SJSC has been reduced from 16.8 years in 2008 (289 single buses with an average age of 13,5 years and 366 twin coach buses with an average age of 19 years) to 7.3 years in 2017.

273 buses run on natural gas, which is over $44 \%$ of the total number. The remaining buses are powered by diesel engines. In 2018, 20 new electric buses with zero CO2 emissions have also been commissioned.

Table 3: Structure of the rolling stock (number) according to the type of used fuel.

\begin{tabular}{|l|l|l|l|l|l|l|l|}
\hline & 2013 & 2014 & 2015 & 2016 & 2017 & 2018 & 2019 \\
\hline \multirow{2}{*}{ diesel } & 550 & 541 & 388 & 456 & 409 & 369 & 323 \\
\cline { 2 - 8 } & $98.57 \%$ & $90.92 \%$ & $74.33 \%$ & $77.29 \%$ & $75.46 \%$ & $61.09 \%$ & $52.44 \%$ \\
\hline \multirow{2}{*}{ CNG } & 8 & 54 & 134 & 134 & 133 & 215 & 273 \\
\cline { 2 - 7 } & $1.43 \%$ & $9.08 \%$ & $25.67 \%$ & $22.71 \%$ & $24.54 \%$ & $35.60 \%$ & $44.32 \%$ \\
\hline \multirow{2}{*}{ electric } & & & & & & 20 & 20 \\
\cline { 5 - 8 } & & & & & & $3.31 \%$ & $3.25 \%$ \\
\hline
\end{tabular}

Source: "Capital Motor Transport" SJSC

As Table 4 indicates, from a total of 616 buses, 378 (or over 61\%) are with the Euro 6 standard. In 2014 buses with the Euro 1, 2 and 3 ecological standards comprise approximately $84 \%$ of the total number, and buses with the Euro 4, 5 and 6 standards $-16 \%$.

\begin{tabular}{|c|l|l|l|l|l|l|l|}
\hline \multicolumn{1}{|c|}{ Table 4: Structure of the rolling stock according to ecological standards } \\
\hline & $\mathbf{2 0 1 3}$ & $\mathbf{2 0 1 4}$ & $\mathbf{2 0 1 5}$ & $\mathbf{2 0 1 6}$ & $\mathbf{2 0 1 7}$ & $\mathbf{2 0 1 8}$ & \multicolumn{2}{|c|}{$\mathbf{2 0 1 9}$} \\
\hline \multirow{2}{*}{ Euro 0 } & 176 & 173 & 86 & 46 & 12 & & \\
\cline { 2 - 8 } & $31.54 \%$ & $29.08 \%$ & $16.48 \%$ & $7.80 \%$ & $2.21 \%$ & & \\
\hline \multirow{2}{*}{ Euro 1 } & 100 & 95 & 29 & 27 & 16 & 4 & \\
\hline & $17.92 \%$ & $15.97 \%$ & $5.56 \%$ & $4.58 \%$ & $2.95 \%$ & $0.66 \%$ & \\
\hline \multirow{2}{*}{ Euro 2 } & 128 & 127 & 127 & 127 & 125 & 99 & 69 \\
\cline { 2 - 8 } & $22.94 \%$ & $21.34 \%$ & $24.33 \%$ & $21.53 \%$ & $23.06 \%$ & $16.39 \%$ & $11.20 \%$ \\
\hline \multirow{2}{*}{ Euro 3 } & 111 & 111 & 111 & 111 & 111 & 111 & 99 \\
\cline { 2 - 8 } & $19.89 \%$ & $18.66 \%$ & $21.26 \%$ & $18.81 \%$ & $20.48 \%$ & $18.38 \%$ & $16.07 \%$ \\
\hline \multirow{2}{*}{ Euro 4 } & 35 & 35 & 35 & 35 & 35 & 35 & 35 \\
\cline { 2 - 8 } & $6.27 \%$ & $5.88 \%$ & $6.70 \%$ & $5.93 \%$ & $6.46 \%$ & $5.79 \%$ & $5.68 \%$ \\
\hline \multirow{2}{*}{ Euro 5 } & 8 & 8 & 8 & 8 & 7 & 17 & 15 \\
\cline { 2 - 8 } & $1.43 \%$ & $1.34 \%$ & $1.53 \%$ & $1.36 \%$ & $1.29 \%$ & $2.81 \%$ & $2.44 \%$ \\
\hline \multirow{2}{*}{ Euro 6 } & & 46 & 126 & 236 & 236 & 318 & 378 \\
\cline { 2 - 8 } & & $7.73 \%$ & $24.14 \%$ & $40.00 \%$ & $43.54 \%$ & $52.65 \%$ & $61.36 \%$ \\
\hline \multirow{2}{*}{ Electric } & & & & & & 20 & 20 \\
\cline { 2 - 7 } & & & & & & $3.31 \%$ & $3.25 \%$ \\
\hline
\end{tabular}

Source: "Capital Motor Transport" SJSC

For analytical purposes, the work examines four main categories of harmful emissions: $\mathrm{CO}$ - Carbon oxide; $\mathrm{CxHx}$ - Hydrocarbons; NOx - Nitrous oxides and Particulates. Table 5 makes it clear that the largest drops in harmful emissions can be seen in buses that run on natural gas, namely:

- CO - Carbon oxide 2019/2008-98\%

- CxHx - Hydrocarbons 2019/2008-80, $4 \%$

- NOx - Nitrous oxides 2019/2008-91,4\%

- Particulates 2019/2008-96,4\%

Table 5: Changes according to bus types and harmful emissions, compared for 2019 with reference to 2008

\begin{tabular}{|c|c|c|c|c|c|c|c|c|c|c|c|c|c|}
\hline \multirow{2}{*}{\multicolumn{2}{|c|}{ Bus Type }} & \multicolumn{12}{|c|}{ Harmful emissions measured in $\mathrm{kg}$ according to bus types and used fuel } \\
\hline & & \multicolumn{3}{|c|}{ CO - Carbon oxide } & \multicolumn{3}{|c|}{ CxHx - Hydrocarbons } & \multicolumn{3}{|c|}{ Nox - Nitrous Oxides } & \multicolumn{3}{|c|}{ Particulates - PM } \\
\hline Size & Engine & 2008 & 2019 & $\%$ & 2008 & 2019 & $\%$ & 2008 & 2019 & $\%$ & 2008 & 2019 & $\%$ \\
\hline 12-m & Diesel & 113021.42 & 95406.33 & $-16 \%$ & 110842.74 & 66962,17 & $7-39.59 \%$ & 923412.22 & 658649.17 & $7-28.67 \%$ & 20618.90 & 12067.46 & $6-41.47 \%$ \\
\hline 18-m & Diesel & 194094.21 & 148153.49 & $-75 \%$ & 144043.32 & 60006.26 & $6-58.34 \%$ & 1302212.64 & 4443039.66 & $5-65.98 \%$ & 32712.07 & 11185.46 & $6-65.81 \%$ \\
\hline 12-m & gas & 10299.52 & 197.98 & $-98 \%$ & 5682.67 & 1113.61 & $-80.40 \%$ & 52095.49 & 4479.20 & $-91.40 \%$ & 1233.26 & 44.54 & $-96.39 \%$ \\
\hline 18-m & gas & - & 24824.56 & & - & 18700.08 & & - & 25396.17 & - & - & 1633.19 & - \\
\hline
\end{tabular}




\begin{tabular}{|l|l|l|l|l|l|l|l|l|l|l|}
\hline 12-m electric- & 0 & - & - & 0 & - & - & 0 & - & - & - \\
\hline Source: Author
\end{tabular}

Naturally, a drop in harmful emissions can also be noticed in diesel buses, which is due to the higher Euro 6 ecological standard.

Generally, for each year, harmful emissions have been dropping annually at an increasing rate from approximately 3 million kg/y. (3000 tons) in 2008 to 1152 tons in 2019 (Table 6).

\begin{tabular}{|l|l|l|l|}
\hline \multicolumn{1}{|c|}{ Table 6: Reducing harmful emissions by years, measured in tons } \\
\hline Year & \multicolumn{1}{|c|}{ t/year } & \multicolumn{1}{c|}{ \% changes } \\
\hline $\mathbf{2 0 0 8}$ & 2910 & - \\
\hline $\mathbf{2 0 0 9}$ & 2721 & $-6.49 \%$ \\
\hline $\mathbf{2 0 1 0}$ & 2611 & $-10.27 \%$ \\
\hline $\mathbf{2 0 1 1}$ & 2392 & $-17.80 \%$ \\
\hline $\mathbf{2 0 1 2}$ & 2380 & $-18.21 \%$ \\
\hline $\mathbf{2 0 1 3}$ & 2134 & $-26.67 \%$ \\
\hline $\mathbf{2 0 1 4}$ & 2123 & $-27.04 \%$ \\
\hline $\mathbf{2 0 1 5}$ & 1693 & $-41.82 \%$ \\
\hline $\mathbf{2 0 1 6}$ & 1619 & $-44.36 \%$ \\
\hline $\mathbf{2 0 1 7}$ & 1472 & $-49.42 \%$ \\
\hline $\mathbf{2 0 1 8}$ & 1250 & $-57.04 \%$ \\
\hline $\mathbf{2 0 1 9}$ & 1152 & $-60.41 \%$ \\
\hline & & \\
\hline
\end{tabular}

For 2019, harmful emissions resulting from actual traversed kilometers or vehicle runs dropped by a total of $60 \%$ due to the commissioning of 20 electric buses.

\section{Conclusion}

It can be noted as an inference that the connection made between the rolling stock's lower average age, the fuel used by buses and the pollution norms under the same operating capacity will make them more environmentally friendly.

According to Tzvetkova (2020), the incorporation of modern and environmentally friendly electrically powered vehicles into the urban transport network should be a fundamental priority in the plan for the future development of the city's public transport. It is imperative that a gradual replacement of all morally outdated and depreciated passenger vehicles in the city be initiated.

The technical condition of the vehicles and the comfort they offer are crucial to the improvement of freight quality. Modern environmentally friendly vehicles are guaranteed to reduce noise and dust pollution, as well as provide tranquility for citizens whose places of residence are located in close proximity to elements of the public transport infrastructure. The incorporation of new technology in electric transport guarantees that the kinetic energy they emit will be converted and reused. This, in turn, leads to savings and reduced losses.

According to Tzvetkova (2019), the achievement of high social and economic effectiveness of urban passenger transport in Sofia is a prerequisite for its stable development. This can be achieved through the adoption and implementation of specific measures which are designed to increase the quality of transport services, reduce energy consumption and improve the quality of the air. All of these measures should become part of the plan for Sofia's stable urban mobility.

\section{References}

Arnaudov, B. (2013) Human Resources Development in Transport. Economic and Social Alternatives, Issue 1, 2013, pp. 143-152.

Center of Urban Mobility - Sofia, https://www.sofiatraffic.bg.

Integrated Transport Strategy for the Period Until 2030.

Report on the Future Activities for Stable Mobility (2015/2005(INI).

The National Strategy for Regional Development (NSRD) of the Republic of Bulgaria for the 2012-2022 Period. 
The Strategy for Development of the Transport System of the Republic of Bulgaria Until 2020.

Tzvetkova, S., (2017), "Increasing the social effectiveness of public transport", CBU International Conference "Innovation in Science and Education", March 22-24 2017, Prague; Conference Proceedings 2017, Vol. 5, p.448, E-ISSN $1805-9961$ (Online), http://dx.doi.org/10.12955/cbup.v5.1114.

Tzvetkova, S., (2018), "Guidelines for Improving the Quality of Urban Passenger Transport in the City of Sofia within the Context of Stable Urban Mobility”, 9th International Conference on Environmental Science and Development - ICESD 2018 IOP Publishing, IOP Conf. Series: Earth and Environmental Science 151, pp. 289-290, 012032 doi:10.1088/1755$1315 / 151 / 1 / 012032$.

Tzvetkova, S., (2019) "Guidelines for the Stable Development of Public Bus Transport in the City of Sofia” 2019 10th International Conference on Environmental Science and Development (ICESD 2019, E 3S Web. Conf. Volume 101, 2019, art. 01003, DOI: https://doi.org/10.1051/e3sconf/201910101003.

Tzvetkova, S., (2020), "Increasing the Social Effectiveness of Public Transport in the City of Sofia", International Journal for Quality Research, Volume 14, Number 1 (2020), pp. 79-92, ISSN 1800-6450, UDC - 005.62:629.34; DOI 10.24874/IJQR14.01-06.

Velikova, E. (2019). Methodological guidelines for the sustainable development of the Bulgarian touristic resorts through reducing the harmful impact of transport. E3S Web of Conferences 101, 01004 (2019) ICESD 2019 https://doi.org/10.1051/e3sconf/201910101004. 